\title{
Presentación dossier
}

\section{FORMACIÓN INICIAL DOCENTE: AVANCES, NUDOS CRÍTICOS Y DESAFÍOS}

La formación inicial docente en Chile ha experimentado en las últimas décadas una serie de reformas, promovidas, en ciertos casos, desde las propias universidades, y en otras ocasiones, desde el Estado. En ambos casos, el objetivo ha sido el mismo, fortalecer de manera sustancial la calidad de la formación de profesoras y profesores. A pesar de ello, se mantienen múltiples nudos críticos en el sistema de formación inicial docente, así como una serie de desafíos de los que las universidades deben hacerse cargo.

En el presente dossier, se abordan temáticas que consideran diversas aristas de la formación inicial docente, en un proceso que abarca, temporalmente, una proyección más amplia que la mera duración de la carrera universitaria. En efecto, las instituciones formadoras de profesoras y profesores se encuentran hoy ante desafíos que hace algunos años no necesariamente asumían, pero que son actualmente insoslayables. Ejemplos de tales desafíos lo constituyen, por un lado, detectar tempranamente, durante la enseñanza secundaria, a estudiantes de buen rendimiento académico y motivados por la carrera pedogógica, con el fin de atraerlos. Por otro lado, en el extremo opuesto, desde el punto de vista temporal, se encuentra el desafío de establecer estrategias y dispositivos que permitan insertar de la manera más fluida posible a los recién egresados al mercado laboral.

En este contexto, nos complace presentar, con el apoyo del equipo directivo de revista Sophia Austral, al que agradecemos muy sinceramente, el dossier "Formación inicial docente: avances, nudos críticos y desafíos”, compuesto de cinco artículos.

El primero de ellos, titulado "Programas de acceso especial a las carreras de Pedagogía: sus características en las Universidades del Estado de Chile”, de los autores N. Hormazábal, N. Abricot, K. Oyarzo, M. Alvarado y C. Bravo, aborda una temática reciente en la evolución de la formación inicial docente de nuestro país: la apertura de las carreras de pedagogía a programas de preparación y acceso especial, pensados de manera exclusiva para estas. Este artículo presenta, desde nuestro punto de vista, un doble valor agregado. Por un lado, los autores pertenecen a cuatro instituciones universitarias distintas, ubicadas entre Santiago y Punta Arenas, lo cual demuestra una red de colaboración importante, en este caso, entre universidades del Estado, que tiene entre sus múltiples objetivos, la formación de profesores 
y profesoras, y que se encuentran al día de hoy trabajando en programas de detección y atracción de estudiantes, para que estos ingresen mediante vía especial a las carreras de Pedagogía. En un periodo de incertidumbres, y en un contexto social y cultural en el que no siempre es fácil mantener el atractivo de la carrera pedagógica, la importancia de estos programas puede ser vital para fortalecerla. El artículo nos invita a descubrir cuáles son las lógicas subyacentes a la creación e implementación de los programas de acceso especial, las que, por cierto, tienen puntos de convergencia, pero también particularidades. Finalmente, más allá de la caracterización de estos programas, el artículo permite orientar el trabajo de las instituciones universitarias que se encuentren implementado, o que estén por iniciar, programas de acceso especial.

Los dos artículos siguientes dicen relación con una temática que se encuentra en el corazón de la formación inicial docente: la didáctica.

Por una parte, en el artículo "Competencias didácticas para la formación inicial de profesores de Chile. Un análisis comparado”, los autores M. Díaz, M. Romero-Jeldres, T. Mardones, S. Castillo y R. Sequeida, en el contexto de un proyecto de mejoramiento institucional de fortalecimiento de la formación de profesores, se exponen los aspectos asociados al Marco para la Buena Enseñanza (MBE) y los Estándares Pedagógicos, describiendo la presencia o ausencia en estos del constructo Competencia Profesional Didáctica, validado inicialmente por Romero-Jeldres y Faouzi $(2018,2020)$, con docentes sin formación pedagógica provenientes de liceos de Educación Media Técnico-Profesional. En este estudio, se utiliza dicho constructo como insumo al contexto de la formación inicial docente. Los resultados del estudio muestran que tanto los Estándares Pedagógicos como el Marco para la Buena Enseñanza consideran primordialmente aspectos relacionados con la acción profesional. Los autores concluyen que, para lograr una formación inicial más integral, es necesario incorporar a estos las competencias sociales, así como la vocación laboral y comunicativa, con el objetivo de dar mayor consistencia al proceso de desarrollo profesional de los docentes, y al mismo tiempo abrir el debate para poner en discusión el concepto de competencia profesional didáctica.

Por otra parte, en el artículo "¿Cómo formar en la didáctica de especialidad a futuros docentes de Educación Básica?”, de los autores R. Gaete, F. Navia, M. Morales, M. Yáñez, J. Neira y G. Moreno, encontramos una propuesta de modelo formativo, que releva la importancia de concebir al profesor de educación general básica como un profesor disciplinar y articulado a la didáctica, sobre la base de modelos didácticos específicos. Este artículo busca exponer y discutir las opciones formativas de trabajar desde una noción de disciplina escolar que reconoce la didáctica como parte integral de la misma en el contexto de la implementación de un proyecto de mejora institucional. Esta investigación, a través de la revisión de diversas fuentes escritas, tales como proyecto original de carrera, programas actuales de asignaturas y literatura especializada, llama a considerar la necesidad de fortalecer una formación didáctica específica y disciplinar, en la medida que las bases teóricas sean coherentes entre 
sí. El artículo considera un camino alternativo a la oposición entre saberes didácticosdisciplinares y pedagógicos, realizando un ejercicio reversible entre ambas dimensiones. El modelo formativo aquí presentado es un esbozo de avance en esta línea, y que se espera, sirva de inspiración a otros equipos que se encuentran en esta misma labor formativa.

De manera complementaria a los dos estudios anteriores, el artículo "Lectura y comprensión de textos en la formación inicial de profesores, avances y principales desafíos de investigación”, de M. Makuc, presenta teorías implícitas relativas a la comprensión de textos en estudiantes universitarios de primer año. Los resultados de este estudio permiten, además de reconocer tres teorías predominantes, relacionar estas teorías con las competencias lectoras de los estudiantes.

El último artículo de este dossier, de P. Ayala, se titula "Influencia de lo adscrito y lo adquirido en el tiempo que tardan los profesores principiantes chilenos en encontrar su primer empleo". Este interesante estudio analiza una temática todavía escasamente explorada, la inserción laboral de los profesores principiantes al sistema escolar chileno, a través de registros provenientes de diversas bases de datos que permiten reconstruir la carrera académica y laboral de casi 25.000 titulados. Destaca, por un lado, la relevancia del origen social (lo adscrito) y, por el otro, la importancia de las credenciales académicas (lo adquirido) de los profesores principiantes, en el tiempo que estos tardan en incorporarse al mercado laboral. Se verifica, finalmente, que mientras más tiempo transcurre tras la titulación, se hace menos probable el ingreso al sistema escolar. En el marco de este dossier, los hallazgos de este estudio permiten relacionar el momento final de la formación inicial docente, es decir, la inserción laboral, con la temática del primer artículo presentado, relativo a los programas de acceso especial a las carreras de Pedagogía, revelando que la formación inicial docente tiene por delante desafíos que implican pensar en ella en una perspectiva amplia y multidimensional.

Dr. Álvaro González Sanzana Universidad de Magallanes alvaro.gonzalez@umag.cl
Dr. Mario Garay Aguilar

Universidad de Magallanes mario.garay@umag.cl 